\title{
Detours in long-distance migration across the Qinghai-Tibetan Plateau: individual consistency and habitat associations
}

\author{
Dongping Liu ${ }^{\text {Corresp.. }}{ }^{1}$ ， Guogang Zhang ${ }^{\text {Corresp.. }}{ }^{1}$, Hongxing Jiang ${ }^{1}$, Jun Lu ${ }^{1}$ \\ ${ }^{1}$ Key Laboratory of Forest Protection of State Forestry Administration, Research Institute of Forest Ecology and Environment Protection, Chinese Academy \\ of Forestry, Beijing, China
}

Corresponding Authors: Dongping Liu, Guogang Zhang

Email address: dpliu@caf.ac.cn, zm7672@126.com

Migratory birds often follow detours when confronted with ecological barriers, and understanding the extent and the underlying drivers of such detours can provide important insights into the associated cost to the annual energy budget and the migration strategies. The Qinghai-Tibetan Plateau is the most daunting geographical barrier for migratory birds because the partial pressure of oxygen is dramatically reduced and flight costs greatly increase. We analyzed the repeated migration detours and habitat associations of four Pallas's Gulls Larus ichthyaetus across the Qinghai-Tibetan Plateau over 22 migration seasons. Gulls exhibited notable detours, with the maximum distance being more than double that of the expected shortest route, that extended rather than reduced the passage across the plateau. The extent of longitudinal detours significantly increased with latitude, and detours were longer in autumn than in spring. Compared with the expected shortest routes, proximity to water bodies increased along autumn migration routes, but detourhabitat associations were weak along spring migration routes. Thus, habitat availability was likely one, but not the only factor shaping the extent of detours, and migration routes were determined by different mechanisms between seasons. Significant betweenindividual variation but high individual consistency in migration timing and routes were revealed in both seasons, indicating a stronger influence of endogenous schedules than local environmental conditions. Gulls may benefit from repeated use of familiar routes and stopover sites, which may be particularly significant in the challenging environment of the Qinghai-Tibetan Plateau. 
1 Detours in long-distance migration across the Qinghai-Tibetan Plateau: individual

2 consistency and habitat associations

3 Dongping Liu*, Guogang Zhang*, Hongxing Jiang, Jun Lu

4 Key Laboratory of Forest Protection of State Forestry Administration, Research Institute of

5 Forest Ecology and Environment Protection, Chinese Academy of Forestry, Beijing, China

6 ABSTRACT

7 Migratory birds often follow detours when confronted with ecological barriers, and

8 understanding the extent and the underlying drivers of such detours can provide important

9 insights into the associated cost to the annual energy budget and the migration strategies. The

10 Qinghai-Tibetan Plateau is the most daunting geographical barrier for migratory birds because

11 the partial pressure of oxygen is dramatically reduced and flight costs greatly increase. We

12 analyzed the repeated migration detours and habitat associations of four Pallas's Gulls Larus

13 ichthyaetus across the Qinghai-Tibetan Plateau over 22 migration seasons. Gulls exhibited

14 notable detours, with the maximum distance being more than double that of the expected shortest

15 route, that extended rather than reduced the passage across the plateau. The extent of longitudinal

16 detours significantly increased with latitude, and detours were longer in autumn than in spring.

17 Compared with the expected shortest routes, proximity to water bodies increased along autumn

18 migration routes, but detour-habitat associations were weak along spring migration routes. Thus,

19 habitat availability was likely one, but not the only factor shaping the extent of detours, and

20 migration routes were determined by different mechanisms between seasons. Significant

21 between-individual variation but high individual consistency in migration timing and routes were

22 revealed in both seasons, indicating a stronger influence of endogenous schedules than local

23 environmental conditions. Gulls may benefit from repeated use of familiar routes and stopover

24 sites, which may be particularly significant in the challenging environment of the Qinghai-

25 Tibetan Plateau. 


\section{INTRODUCTION}

Migratory birds often follow detours, which are spatial deviations from the most direct route, to minimize energy expenditure or travel time and ultimately arrive at their destinations safely and optimally (Alerstam, 2001, 2011). Although birds travel longer distances and incur extra energetic costs with migration detours, they can be sufficiently compensated by reducing the risk of disturbance and predation (Klaassen et al., 2006; Ydenberg, Butler \& Lank, 2007), reducing costs in time to fuel in high-quality stopover sites (Lindström et al., 2011; Aharon-Rotman et al., 2016), or reducing energetic costs to fly in favourable wind conditions (Vansteelant et al., 2017; Tøttrup et al., 2017). When confronted with a heterogeneous environment regarding to topography, weather condition and food availability, long-distance migrants might have a great capacity to follow variable degree of detours that are characterized by a combination of favorable factors (Hahn et al., 2014). Analysing the extent of detours as well as the environmental conditions experienced en route is crucial for determining why birds employ such migration strategies and the underlying drivers.

Mountain ranges, oceans, deserts, ice fields, and bad-weather fronts constitute the main ecological barriers to migratory birds (Berthold, 2001). To accomplish a non-stop, long-distance flight over an extensive barrier, migratory birds require heavy fuel loads, whose transport incur extra energetic costs (Gill et al., 2009). Therefore, to minimize energetic expenditures, birds usually take a detour in the optimum route that includes a shortcut across part of the barrier (Alerstam, 2001). Previous studies have primarily focused on migration detours across ecological barriers such as deserts, oceans and bad weather fronts (Mellone et al., 2011; Hawkes et al., 2013; Smolinsky et al., 2013; Hahn et al., 2014; Vansteeland et al., 2016), but the performance of migrants confronted with the challenging environment of high plateaus remains poorly explored, although this type of migration has been documented in a few species (Zhang et al., 2011b, 2014; Liu et al., 2012; Hawkes et al., 2013). Compared to travel over oceans and deserts, birds migrating over high plateaus must overcome the disadvantage of a reduced partial pressure of oxygen by increasing their metabolic rates (Scott, 2011; Hawkes et al., 2013), and 
53

54

55

56

57

58

59

60

61

62

spend more energy during flapping flight due to the reduced lift generation in thinner air (Pennycuick, 2008). However, birds can make stopovers on plateaus when necessary, and take advantage of the predictable daily slope winds to climb high plateaus (Hawkes et al., 2011). Consequently, this may result in different detour patterns among migratory birds encountering high plateaus.

Endogenous programmes largely control the migration schedule (Berthold, 1996), but environmental conditions (e.g., climate conditions and food availability) also greatly affect migration flexibility, especially at the individual level (Both, 2010; Studds \& Marra, 2011). Generally, strong endogenous control results in lower within- (i.e., individual consistency) than between-individual variation in migration schedules over successive years, whereas environmental conditions have the opposite effect (Vardanis et al., 2011; López-López, GarcíaRipollés \& Urios, 2014). Therefore, analysing the variation in repeated migration tracks taken by long-distance migrants is an important way to assess the degree of flexibility in migration and understand the adaptive migration strategies under environment pressures.

In this study, we analysed the long-distance migration in Pallas's Gull Larus ichthyaetus between Qinghai Lake in northwestern China and Bangladesh Bay as revealed by satellite tracking. En route, the gulls were confronted with the geographical barrier of the QinghaiTibetan Plateau (hereafter, QTP), which is the world's highest and largest plateau with an average elevation exceeding 4,500 $\mathrm{m}$ and an area of 2,500,000 $\mathrm{km}^{2}$ (Zhang, Li \& Zheng, 2002). It is a great challenge for birds to migrate at extremely high altitudes because the partial pressure of oxygen is dramatically reduced, which greatly increases flight costs (Pennycuick, 2008; Hawkes et al., 2013; Parr et al., 2017), so the gulls were expected to follow detours to minimize exposure to inhospitable environments on the ground. We analysed the spatial patterns of the detours and compared the differences in migration routes and timing between autumn and spring to test for variations in seasonal migration strategies. All individuals were tracked during consecutive years (from two to four years); so we were able to compare between- and withinindividual variation in migration routes and timing to assess the degree of repeatability in 
80

81

82

83

84

migration detours and schedules. We also compared habitat composition along the observed routes and the expected shortest routes to assess the relationship between migration detours and habitat availability.

\section{METHODS}

\section{Satellite tracking and location data processing}

We tracked four Pallas's Gulls (denoted G1 to G4) breeding at Qinghai Lake (99.36-100.77 E, $36.32-37.25^{\circ} \mathrm{N}$; altitude $\left.=3200 \mathrm{~m}\right)$ in northwestern China by satellite telemetry $(12 \mathrm{~g}$ PTT-100; Microwave Telemetry Inc., Columbia, MD, USA; duty cycle $8 \mathrm{~h}$ on / 15 h off) during 2006-2009 (Zhang et al., 2014). We received the Doppler-derived PTT location information from the $\mathrm{CLS} /$ Service Argos satellite tracking system that reports 1-sigma error radii of 150-1000 $\mathrm{m}$ to reflect the location accuracy of location classes (LC) 1, 2 and 3 (Argos, 1996); LC 0, A, B and Z are not assigned accuracy estimates but provide a large amount of relatively accurate data that can be used to analyse gross movements after being filtered (Soutullo et al., 2007). We used the Douglas Argos-Filter Algorithm (v. 8.50) to identify and remove implausible auxiliary Doppler locations based on the distance moved, movement rate, and turning angle (Douglas et al., 2012). Only locations recorded during complete migratory journeys (those that covered the entire distance between the breeding and wintering grounds) were included in this study.

\section{Parameters for migration timing and routes}

For each bird and migratory season, we recorded a set of parameters to describe migration timing and routes that included departure date, arrival date, duration, shortest distance (the great-circle distance between the breeding and wintering site), cumulative distance (the total great-circle distance of the migration segments) and the average migration speed (calculated as the cumulative distance/duration). We plotted telemetry locations in Google Earth Pro (version 7.1.8.3036, Google Inc.) to determine migration timing parameters by visually inspecting the raw data and determining the habitat of the stopover sites. If the PTTs did not transmit continuously, we used the median date between the last point at the previous location and the first point of the 
new location to calculate timing. We plotted the telemetry locations in ArcView GIS (version 3.3; Environmental Systems Research, Redlands, California) and used the XTools extension to compute route distance. We also calculated the straightness index as the ratio between the shortest distance and the cumulative distance to roughly measure the degree of the migration detours.

To explore the spatial and temporal patterns of the migration of Pallas's Gulls across the QTP, we recorded the parameters of trans-QTP duration, trans-QTP distance and trans-QTP speed (calculated as the trans-QTP distance/trans-QTP duration). For this study, the QTP was defined as the areas above $3000 \mathrm{~m}$ in altitude, and we contoured it in ArcView GIS and computed the trans-QTP distance of each migration route using the XTools extension. To assess the topographical preference for migration, we determined the mean altitude of each route, which was automatically generated in Google Earth by plotting the migration routes in the software. The southern and the northern QTP is crossed by two representative latitudes, $29^{\circ} \mathrm{N}$ and $35^{\circ} \mathrm{N}$, so we recorded the longitudes crossing these two latitudes to test the spatial flexibility of the repeated migration routes across the QTP.

\section{Longitudinal detours in migration routes}

To assess the degree of longitudinal detours in migration routes by individuals within each season, we compared each observed route with 1000 randomized routes that were automatically generated by rearranging each segment of the observed route using the Alternate Animal Movement Route extension for ArcView GIS (Jenness, 2005; López-López, García-Ripollés \& Urios, 2014). Each randomized route had the same number and sequence of segments but a different segment orientation from the observed route. We recorded the longitudes crossing each $3^{\circ}$ latitude interval from $23^{\circ} \mathrm{N}$ to $44^{\circ} \mathrm{N}$ for each observed route and the 1000 simulated routes (i.e., the randomly generated routes). If a bird doubled back during the migration, resulting in two or more longitude values crossing a specific latitude, the most longitudinally deviated value was used. If the observed longitudes for a bird fell below the 2.5 th percentile or above the 97.5 th percentile (equivalent to a two-tailed test with $P=0.05$ ) of the 1000 randomly generated 
134 longitudes, the observed longitudes were considered to have significantly deviated from the 135 possible routes (López-López, García-Ripollés \& Urios, 2014) (Fig. S1).

136 To measure the extent of longitudinal detours, we calculated the linear distance of the maximum longitudinal deviation of each observed route from the expected shortest route at $3^{\circ}$ latitude intervals from $23^{\circ} \mathrm{N}$ to $44^{\circ} \mathrm{N}$. When the gulls overshot the breeding site or wintering site, we calculated the linear distance of the maximum longitudinal deviation of the overshot segment from the breeding site or wintering site. In this case, we also calculated the linear distance of the maximum latitudinal deviation of overshot stopover sites from the breeding site or wintering site as a measurement of latitudinal detour (Fig. S2).

\section{Detours and habitat association}

Pallas's Gulls exclusively use open water as stopover sites for refuelling, so the availability of open water may have profound influence on migration route selection (Zhang et al., 2011a). We analysed the proximity to water bodies based on the China National River System Data Set (http://www.pudn.com/downloads608/sourcecode/graph/detail2478372.html), which comprises information on third-order rivers and lakes with areas $\geq 0.01 \mathrm{~km}^{2}$ in China. The composition of lakes and rivers was extracted from zones with $100 \mathrm{~km}$ buffers around the observed and expected shortest routes in ArcView GIS, and the differences between the zones were then compared to assess migration detours and habitat associations. We did not analyse detours and habitat associations for the southern stretches of the route outside China because all individuals were funnelled through a narrow corridor to the wintering site, which was spatially near the expected shortest routes.

\section{Statistical analyses}

We checked the data for normality to determine whether the use of parametric or nonparametric tests. We used paired $t$-tests or Wilcoxon signed-rank tests to compare the differences between average migration speed and trans-QTP speed for each route and determine the differences in proximity to water bodies between the observed and expected shortest routes. We compared the longitudinal variation across the QTP by ANOVA, with individual and season as factors, and we 
161

162

163

164

165

166

167

168

169

170

171

172

173

174

175

176

177

178

179

180

181

182

183

184

185

186

187

analysed the seasonal differences in migration route and timing parameters using GLM mixed models, with individual as a random factor. We also used GLM mixed models to compare the between- and within-individual variation in the timing and route of repeated migration tracks. Based on the derived variance components, we calculated the repeatability (i.e., intra-individual correlation coefficient; Lessells \& Boag, 1987) of migration timing and route to measure how consistently individuals differed from each other. All statistical analyses were performed using the SPSS statistical software package (version 22.0, IBM 2013), and the results were calculated as a mean $\pm \mathrm{SD}$, with a 0.05 level of significance based on two-tailed tests.

\section{Ethical note}

All data collected as part of this study were approved by the National Bird Banding Center of China (No. NBBC20060407). The field work was approved by the State Forestry Administration (No. 33 Forestry Protection [2002]).

\section{RESULTS}

The complete data set for the four tracked Pallas's Gulls contained 2196 positions, consisting of $32.5 \%$ high-quality locations (LC 1-3). Overall, we obtained data for 22 complete migratory journeys (12 in autumn and 10 in spring), with the four birds repeatedly tracked across the QTP between Qinghai Lake in north-western China and Bangladesh Bay for two to four consecutive years (Table 1, Fig. 1).

\section{Spatial patterns of detours}

Notable detours were observed along the migration routes in both seasons (Fig. 1). Gulls exhibited increasing longitudinal detour extents from south to north across the migration routes in both autumn (chi-square test for trend, $\left.X^{2}=6.627, d f=1, P=0.010\right)$ and spring $\left(X^{2}=4.151\right.$, $d f=1, P=0.042$ ) (Fig. 2), with the largest detours being $1068 \mathrm{~km}$ at $38^{\circ} \mathrm{N}$ in autumn and 685 $\mathrm{km}$ at $32^{\circ} \mathrm{N}$ in spring. Similarly, the percentage of the observed routes that significantly deviated from the simulated routes increased from south to north in autumn $\left(X^{2}=5.955, d f=1, P=\right.$ 0.015). 
After departure from Qinghai Lake in seven $(n=12)$ autumn migration seasons, three of the four gulls exhibited notable northward migration outside of the QTP to stopover sites at lower altitudes $(\Delta$ altitude $=2337 \pm 385$ m compared with Qinghai Lake, $\mathrm{n}=7$; Fig. 1$)$, with an average latitudinal detour of $627 \pm 275 \mathrm{~km}$ (range $=133-799 \mathrm{~km}, \mathrm{n}=7)$. Similarly, in five $(\mathrm{n}=10)$ spring migration seasons, two of the four gulls overshot the breeding grounds to farther northern stopover sites at lower altitudes $(\Delta$ altitude $=2029 \pm 139$ m compared with Qinghai Lake, $\mathrm{n}=5$ ) and then reverse migrated back to Qinghai Lake, with an average latitudinal detour of $168 \pm 24$ $\mathrm{km}($ range $=140-193 \mathrm{~km}, \mathrm{n}=5)$.

Relative to the expected shortest routes, gulls travelled $1210 \pm 1002 \mathrm{~km}$ (range $=81-2240 \mathrm{~km}, \mathrm{n}$ $=12)$ or $61.3 \pm 50.4 \%($ range $=4.5 \%-123.2 \%, \mathrm{n}=12)$ of additional detour distance in autumn and $860 \pm 648 \mathrm{~km}($ range $=63-1762 \mathrm{~km}, \mathrm{n}=10)$ or $45.3 \pm 34.6 \%($ range $=2.8 \%-95.0 \%, \mathrm{n}=10)$ in spring. Gulls covered significantly longer trans-QTP distances along the observed routes than along the shortest routes both in autumn (paired $t$-test, $t=6.52, d f=11, P<0.001$ ) and in spring $(t=3.97, d f=9, P=0.003)$.

\section{Temporal patterns of detours}

Gulls used different routes in different seasons and followed a loop migration pattern (Fig. 1). On average, gulls followed larger longitudinal detours in autumn than in spring at all eight measured latitudes from $23^{\circ} \mathrm{N}$ to $44^{\circ} \mathrm{N}$ (Wilcoxon signed-rank test, $Z=-2.521, P=0.008$ ) (Fig. 2). The effect of season on longitudinal variation was strong at $35^{\circ} \mathrm{N}$ (ANOVA, $F=16.46, d f=1$, $\left.P=0.001, \mathrm{~h}^{2}=0.540\right)$ but weak at $29^{\circ} \mathrm{N}(F=0.68, d f=1, P=0.424)$, reflecting that the loop migration primarily occurred across the northern part of the QTP. A significant individual $\times$ season interaction was detected both at $35^{\circ} \mathrm{N}\left(F=9.47, d f=3, P=0.001, \mathrm{~h}^{2}=0.670\right)$ and $29^{\circ} \mathrm{N}$ $\left(F=18.33, d f=3, P<0.001, \mathrm{~h}^{2}=0.797\right)$, indicating that different individuals migrated in different loops or even followed loops in different directions (i.e., clockwise or counter clockwise; Fig. 1).

No significant seasonal differences were observed in the migration route parameters, including cumulative distances, trans-QTP distances, straightness and mean altitude (GLM mixed models, 
$\left.215 F_{1,20}=0.10-0.31, P=0.618-0.778\right)$. However, the spring migration duration was significantly

216 shorter than that in autumn (GLM mixed models, $F_{1,20}=22.38, P=0.018$ ). Additionally, no

217 significant differences were detected in trans-QTP duration, average speed and trans-QTP speed

218 (GLM mixed models, $\left.F_{1,20}=0.23-2.88, P=0.188-0.424\right)$ between autumn and spring (Table 1).

219 Gulls migrated faster across the QTP than during the entire journey both in autumn and spring

220 (Table 1), but the differences were not significant (Wilcoxon signed-rank test, autumn: $Z=1.413$, $221 \quad P=0.170$; spring: $Z=0.867, P=0.418)$.

\section{Detours and habitat associations}

223 During the autumn migration, we found significantly increased (paired $t$-test, $t=2.90, d f=11, P$

$224=0.015$; Fig. 3) proximity to water bodies along the observed detour routes $(1.3 \pm 0.7 \%, \mathrm{n}=12)$

225 than on the expected shortest routes $(0.7 \pm 0.2 \%, \mathrm{n}=12)$. However, we did not detect a 226 significant difference in proximity to water bodies (paired $t$-test, $t=0.49, d f=9, P=0.635$ )

227 between the observed detour routes $(0.8 \pm 0.7 \%, \mathrm{n}=10)$ and the expected shortest routes $(0.7 \pm$ $2280.1 \%, \mathrm{n}=10)$ in spring.

\section{Individual consistency in detours}

230 The effect of the individual was significant for almost all migration variables, except for several 231 timing variables in autumn (Table 2). Tests of within-individual variation showed that migration variables were more repeatable in spring than in autumn and in route than in timing. In autumn, the departure date was highly flexible $(r=-0.07)$, but the arrival date was highly repeatable $(r=$ 0.85); however, both the departure and arrival date were consistent, for which individuals differed between years by an average of $\pm 6.1 \mathrm{~d}$ and $\pm 3.5 \mathrm{~d}$, respectively. In spring, both the departure date $(r=0.84)$ and arrival date $(r=0.78)$ were highly repeatable; however, gulls showed consistent departure date and somewhat flexible arrival date, for which individuals differed between years by an average of $\pm 4.5 \mathrm{~d}$ and $\pm 14.0 \mathrm{~d}$, respectively. The longitude crossing $35^{\circ} \mathrm{N}\left(r_{\text {autumn }}=0.82, r_{\text {spring }}=0.91\right)$ and $29^{\circ} \mathrm{N}\left(r_{\text {autumn }}=0.75, r_{\text {spring }}=0.89\right)$ in both seasons had high repeatability. In autumn, the within-individual variation of the longitude crossing $35^{\circ} \mathrm{N}$ and $29^{\circ} \mathrm{N}$ between years averaged $201 \mathrm{~km}(6.4 \%$ of the accumulated distance) and $224 \mathrm{~km}(7.1 \%$ of the 
242 accumulated distance), respectively. In spring, the variation averaged $84 \mathrm{~km}(3.0 \%$ of the 243 accumulated distance) and $138 \mathrm{~km}$ (4.9\% of the accumulated distance), respectively. Therefore, 244 gulls showed higher consistency in routes across the QTP in spring than in autumn.

\section{DISCUSSION}

247

We reported on the detours of a long-distance migrant confronted with the geographical barrier of the QTP. The maximum distance of the observed route was more than double that of the expected shortest route. Unusually, gulls followed notable latitudinal detours that accounted for up to half of the total latitudinal extent between the breeding and wintering grounds, and to the best of our knowledge, this detour is one of the largest in avian migration (Alerstam, 2001; Mellone et al., 2011). Although our dataset was relatively small, this study provides important insights into the cost of migratory detours in terms of the annual energy budget of an individual as well as the factors underlying these detours across a high plateau.

Migratory birds are expected to detour to shortcut across part of a barrier because non-stop, long-distance flights demand extra energetic costs to transport the required heavy fuel loads (Alerstam, 2001). However, although detours occurred, the Pallas's Gulls extended rather than reduced the trans-QTP distance compared with the shortest route because the birds could refuel at a couple of stopover sites on the QTP (Zhang et al., 2014). How did gulls compensate for the extra energetic costs of the detours, and what was the justification for the latitudinal detours to low-altitude stopover sites, as climbing up and down the QTP might have incurred extra costs?

Birds sometimes follow detours or even perform reverse migrations to seek better fuelling sites before undertaking long-distance migratory flights across ecological barriers (Lindström et al., 2011; Smolinsky et al., 2013; D'Amico et al., 2014). In our study, gulls (G2, G3 and G4) migrated northward to stopover sites at significantly lower altitudes in autumn and stayed for considerable durations (range $=50-83$ days; Data S1). The energetic costs of locomotion are reduced at lower altitudes because a lower metabolic rate can be maintained (Scott, 2011; Hawkes et al., 2013). All these stopover sites were identified as water bodies, including lakes 
269 (Fig. 4A-B), reservoir (Fig. 4C) and stretches of the Yellow River (Fig. 4D). We suggest that 270 gulls might use the different food compositions at low-altitude stopover sites to their advantage, 271 changing their diet to rapidly increase body mass before migrating across the challenging plateau 272 (Bairkein, 1998; Mcwilliams et al., 2004). Additionally, these areas might also be used for moulting since gulls stayed there from August to October and many waterbirds tend to follow detour in moult migration (Mosbech et al., 2012; Solovyeva et al., 2014). Considering that 275 Pallas's Gulls made an average of two stopovers during a 3000-km journey (Data S1), i.e., employed a "skipping" migration strategy (Piersma, 1987), the quality of stopover sites is especially crucial for long-distance, non-stop flights, so the search for better fuelling sites is probably the drivers underlying the detours. The results of our GIS-based habitat analysis, which revealed increased proximity to water bodies along autumn migration routes relative to the shortest routes, also supported this conclusion. Along spring migration routes, however, a weak detour-habitat association was detected. This means that habitat availability might be one, but not the only driver shaping detour extent (Hahn et al., 2014), and migration routes were shaped under different mechanisms during autumn and spring.

Weather conditions are another important factor shaping migration detours. To avoid the influence of cold weather, Relict Gulls (Larus relictus) follow more southward routes in spring compared to autumn to seek favourable fuelling sites (Liu et al., 2017), and in case of an unexpected adverse weather event, birds might even perform reverse migration (Senner et al., 2015). In our study, the onset of spring migration for G1 was nearly 20 days earlier than that of the other three individuals (Table 1), so consequently, G1 overshot its frozen breeding ground at Qinghai Lake and stayed at a warmer north-eastern stopover site on a stretch of the Yellow River from mid-March to early April during 2007-2009 (Fig. 5).

292 The Pallas's Gulls followed different detours between seasons and therefore exhibited loop migration, which has also been documented in other Larus species (Liu et al., 2017). Avian migrants often face seasonal differences in the prevailing winds along their migration flyway. To achieve optimal migration, bird might overcompensate and overdrift for side winds and 
296

297

298

299

300

301

302

303

304

305

306

307

308

309

310

311

312

313

314

315

316

317

318

319

320

321

322

consequently follow detours and seasonally different routes (Vansteelant et al., 2017). In certain geographical areas, assistance (or hindrance) by the wind may be persistent during migratory flight, depending on the migratory direction of the birds relative to the prevailing wind conditions. It has been documented that supporting winds are significantly more frequent during spring migration than in autumn and up to twice as frequent at higher altitudes, which substantially impacts the timing of seasonal migration in many birds (Sinelschikova et al., 2007; Kemp et al., 2010). Although similar distances were covered, the Pallas's Gulls in our study migrated significantly faster in spring than in autumn; at their extremes, the gulls accomplished the spring migration in less than six days at a migration speed of more than $360 \mathrm{~km} / \mathrm{day}$. This strategy is crucial for gulls that communally breed on islands because nest site competition profoundly affects reproductive success; e.g., nests of late breeders suffer flooding at the foots of islands (Burger \& Shisler, 1980; Miao, 2014).

Our results showed significant between-individual variation but high within-individual repeatability in migration timing and route in both seasons. Although the high repeatability of spring arrival date mispresented the consistency due to the relatively high between-individual variation (i.e. population variation; Conklin, Battley \& Potter, 2013), the departure date and arrival date were in general quite consistent between years. This indicated a stronger influence of endogenous schedules over local environmental conditions, which was consistent with the results of many previous studies (Vardanis et al., 2011; Stanley et al., 2012; López-López, GarcíaRipollés \& Urios, 2014). Compared with migration timing, Pallas's Gulls were even more consistent in their migration route, although different individuals used different detour schemes. Birds could benefit from repeated use of familiar routes and stopover sites by reducing predation risk (Yoder, Marschall \& Swanson, 2004) and energetic costs in a search for new sites, which may be of particular significance under the challenging environmental conditions of the QTP.

In conclusion, Pallas's Gulls confronted with the QTP exhibited notable detours that differed significantly in extent between seasons. Despite the extra energetic costs of repeatedly climbing up and down the QTP, gulls exhibited latitudinal detours to significantly lower-altitude stopover 
323

324

325

326

327

328

329

330

331

332

333

334

335

336

337

338

339

340

341

342

343

344

345

346

347

348

349

sites for considerable fuel loading, which has not been observed in other typical species, such as Bar-headed Goose Anser indicus and Black-necked Crane Grus nigricollis that migrate across the QTP (Zhang et al., 2011b; Liu et al., 2012). Further investigation is needed to shed light on this novel migration strategy under the challenging environment of the QTP.

\section{ACKNOWLEDGMENTS}

We thank the Qinghai Lake National Nature Reserve Bureau for logistically support of the fieldwork. We thank Yunqiu Hou, Ming Dai, Kai Shan, Yuansheng Hou and Yanming Wang for their assistance with the fieldwork and Guang Deng for his assistance with the GIS analysis. We also thank Krysta Black-Mazumdar and Sarah Conte for improving the English as well as Lucy Hawkes and an anonymous reviewer for their valuable and constructive comments on earlier drafts of the manuscript.

\section{REFERENCES}

Aharon-Rotman Y, Gosbell K, Minton C, Klaassen M. 2016. Why fly the extra mile? Latitudinal trend in migratory fuel deposition rate as driver of trans-equatorial long-distance migration. Ecology \& Evolution 6(18):6616-6624.

Alerstam T. 2001. Detours in bird migration. Journal of Theoretical Biology 209:319-331.

Alerstam T. 2011. Optimal bird migration revisited. Journal of Ornithology 152(1 Supplement):5-23.

Argos. 1996. Argos User's Manual. Argos Service, Toulouse, France.

Bairkein F. 1998. The effect of diet composition on migratory fuelling in Garden Warblers Sylvia borin. Journal of Avian Biology 29:546-551.

Berthold P. 1996. Control of Bird Migration. London: Chapman \& Hall.

Berthold P. 2001. Bird Migration: A General Survey. New York: Oxford University Press.

Both C. 2010. Flexibility of timing of avian migration to climate change masked by environmental constraints en route. Current Biology 20(3):243-8. 
350

351

352

353

354

355

356

357

358

359

360

361

362

363

364

365

366

367

Burger J, Shisler J. 1980. Colony and nest site selection in Laughing Gulls in response to tidal flooding. Condor 82(3):251-258.

Conklin JR, Battley PF, Potter MA. 2013. Absolute consistency: Individual versus population variation in annual-cycle schedules of a long-distance migrant bird. PloS One 8(1):e54535. doi: 10.1371/journal.pone.0054535.

D'Amico VL, González PM, Morrison RIG, Baker AJ. 2014. Reverse movements of Red Knots Calidris canutus during northward migration in Argentina. Ardeola Revista Ibérica De Ornitología 61(1):63-76.

Douglas DC, Rolf W, Sarah CD, Rol K, Martin W, Gil B. 2012. Moderating Argos location errors in animal tracking data. Methods in Ecology and Evolution 3(6):999-1007.

Gill RE, Tibbitts TL, Douglas DC, Handel CM, Mulcahy DM, Gottschalck JC, Warnock N, McCaffery BJ, Battley PF, Piersma T. 2009. Extreme endurance flights by landbirds crossing the Pacific Ocean: ecological corridor rather than barrier? Proceedings of the Royal Society B Biological Sciences 276(1656):447-457.

Hawkes LA, Balachandran S, Batbayar N, Butler PJ, Chua B, Douglas DC, Frappell PB, Hou Y, Milsom WK, Newman SH, Prosser DJ, Sathiyaselvam P, Scott GR, Takekawa JY, Natsaqdori T, Wikelski M, Witt MJ, Yan B, Bishop CM. 2013. The paradox of extreme highaltitude migration in bar-headed geese Anser indicus. Proceedings of the Royal Society B Biological Sciences 280(1750):20122114.

Hawkes LA, Balachandran S, Batbayar N, Butler PJ, Frappell PB, Milsom WK, Tseveenmyadag N, Newman SH, Scott GR, Sathiyaselvam P, Takekawa JY, Wikelski M, Bishop CM. 2011. The trans-Himalayan flights of bar-headed geese (Anser indicus). Proceedings of the National Academy of Sciences of the United States of America 108(23):9516-9519.

Hahn S, Emmenegger T, Lisovski S, Amrhein V, Zehtindjiev P, Liechti F. 2014. Variable detours in long-distance migration across ecological barriers and their relation to habitat availability at ground. Ecology and Evolution 4(21):4150-4160. 
376

377

378

379

380

381

382

383

384

385

386

387

388

389

390

391

392

393

394

395

396

397

398

399

400

401

402

Jenness J. 2005. Alternate animal movement routes extension for ArcView 3.x, v. 2.1. Available at http://www.Jennessent.com/arcview/alternate_routes.htm (accessed 10 March 2017).

Kemp MU, Shamoun-Baranes J, Gasteren HV, Bouten W, Loon EEV. 2010. Can wind help explain seasonal differences in avian migration speed? Journal of Avian Biology 41(6):672677.

Klaassen M, Bauer S, Madsen J, Tombre I. 2006. Modelling behavioural and fitness consequences of disturbance for geese along their spring flyway. Journal of Applied Ecology 43:92-100.

Lessells CM, Boag PT. 1987. Unrepeatable repeatabilities: a common mistake. Auk 104:116-121.

Lindström A, Jr REG, Jamieson SE, McCaffery B, Wennerberg L, Wikelski M, Klaassen M. 2011. A puzzling migratory detour: are fueling conditions in Alaska driving the movement of juvenile Sharp-Tailed Sandpipers? Condor 113(1):129-139.

Liu D, Zhang G, Jiang H, Chen L, Meng D, Lu J. 2017. Seasonal dispersal and longitudinal migration in the Relict Gull Larus relictus across the Inner-Mongolian Plateau. PeerJ 5:e3380 https://doi.org/10.7717/peerj.3380.

Liu Q, Li FS, Buzzard P, Qian FW, Zhang F, Zhao JL, Yang JX, Yang XJ. 2012. Migration routes and new breeding areas of Black-necked Cranes. The Wilson Journal of Ornithology 124(4):704-712.

López-López P, García-Ripollés C, Urios V. 2014. Individual repeatability in timing and spatial flexibility of migration routes of trans-saharan migratory raptors. Current Zoology 60(5):642652.

Mcwilliams SR, Guglielmo C, Pierce B, Klaassen M. 2004. Flying, fasting, and feeding in birds during migration: a nutritional and physiological ecology perspective. Journal of Avian Biology 35(5):377-393.

Mellone U, Limiñana R, Mallia E, Urios V. 2011. Extremely detoured migration in an inexperienced bird: interplay of transport costs and social interactions. Journal of Avian Biology 42(5):468-472. 
403

404

405

406

407

408

409

410

411

412

Miao C. 2014. Research and Conservation of Relict Gull. China Forestry Publishing House, Beijing (in Chinese).

Parr N, Bearhop S, Douglas DC, Takekawa JY, Prosser DJ, Newman SH, Perry WM, Balachandran S, Witt MJ, Hou Y, Luo Z, Hawkes LA. 2017. High altitude flights by ruddy shelduck Tadorna ferruginea during trans-Himalayan migrations. Journal of Avian Biology. doi:10.1111/jav.01443.

Pennycuick CJ. 2008. Modelling the Flying Bird. London, UK: Academic Press.

Piersma T. 1987. Hop, skip, or jump? Constraints on migration of arctic waders by feeding, fattening, and flight speed. Limosa 60:185-194.

Scott G R. 2011. Elevated performance: the unique physiology of birds that fly at high altitudes. Journal of Experimental Biology 214(15):2455-62.

Senner NR, Verhoeven MA, Abad-Gómez JM, Gutierrez JS, Hooijmeijer JCEW, Kentie R, Masero JA, Tibbitts TL, Piersma T. 2015. When Siberia came to the Netherlands: the response of continental black-tailed godwits to a rare spring weather event. Journal of Animal Ecology 84(5):1164.

Sinelschikova A, Kosarev V, Panov I, Baushev AN. 2007. The influence of wind conditions in Europe on the advance in timing of the spring migration of the song thrush (Turdus philomelos) in the south-east Baltic region. International Journal of Biometeorology 51(5):431-40.

Smolinsky JA, Diehl RH, Radzio TA, Delaney DK, Mooreet FR. 2013. Factors influencing the movement biology of migrant songbirds confronted with an ecological barrier. Behavioral Ecology and Sociobiology 67:2041-2051.

Solovyeva D, Newton J, Hobson K, Fox JW, Afanasyev V, Fox AD. 2014. Marine moult migration of the freshwater Scaly-sided Merganser Mergus squamatus revealed by stable isotopes and geolocators. Ibis 156(2):466-471. 
428 Soutullo A, Cadahia L, Urios V, Ferrer M, Negro JJ. 2007. Accuracy of lightweight satellite 429 telemetry: a case study in the Iberian Peninsula. Journal of Wildlife Management 71(3):1010$430 \quad 1015$.

431 Stanley CQ, MacPherson M, Fraser KC, McKinnon EA, Stutchbury BJM. 2012. Repeat tracking 432 of individual songbirds reveals consistent migration timing but flexibility in route. Plos One 433 7(7): e40688. doi: 10.1371/journal.pone.0040688.

434 Studds CE, Marra PP. 2011. Rainfall-induced changes in food availability modify the spring 435 departure programme of a migratory bird. Proceedings of the Royal Society B-Biological $436 \quad$ Sciences 278:3437-3443.

437 Tøttrup AP, Pedersen L, Onrubia A, Klaassen RHG, Thorup K. 2017. Migration of red-backed 438 shrikes from the Iberian Peninsula: optimal or sub-optimal detour? Journal of Avian Biology $439 \quad \mathbf{4 8}(1) 149-154$.

440 Vardanis Y, Klaassen RH, Strandberg R, Alerstam T. 2011. Individuality in bird migration: $441 \quad$ routes and timing. Biology Letters 7:502-505.

442 Vansteelant WM, Shamoun-Baranes J, Van MW, Van DJ, Bouten W. 2017. Seasonal detours by 443 soaring migrants shaped by wind regimes along the East Atlantic Flyway. Journal of Animal 444 Ecology 86(2):179-191.

445 Ydenberg RC, Butler RW, Lank DB. 2007. Effects of predator landscapes on the evolutionary 446 ecology of routing, timing and molt by long-distance migrants. Journal of Avian Biology $447 \quad 38: 523-529$.

448 Yoder JM, Marschall EA, Swanson DA. 2004. The cost of dispersal: predation as a function of 449 movement and site familiarity in ruffed grouse. Behavioral Ecology 15:469-476.

450 Zhang GG, Liu DP, Hou YQ, Dai M, Lu J. 2011a. Seasonal changes in waterbirds population 451 and movements of Great Black-headed Gull Larus ichthyaetus at Keluke Lake of Qinghai. 452 Acta Ecologica Sinica 31(15):4398-4404 (in Chinese). 
453 Zhang GG, Liu DP, Hou YQ, Jiang HX, Dai M, Qian FW, Lu J, Ma T, Chen LX, Xing Z, Li FS.

454 2014. Migration routes and stopover sites of Pallas's Gulls Larus ichthyaetus breeding at 455 Qinghai Lake, China, determined by satellite tracking. Forktail 30:104-108.

456 Zhang GG, Liu DP, Hou YQ, Jiang HX, Dai M, Qian FW, Lu J, Xing Z, Li FS. 2011 b.

457 Migration routes and stop-over sites determined with satellite tracking of Bar-Headed Geese 458 Anser indicus breeding at Qinghai Lake, China. Waterbirds 34(1):112-116.

459 Zhang YL, Li BY, Zheng D. 2002. A discussion on the boundary and area of the Tibetan Plateau 460 in China. Geographical Research 21(1):1-8. 


\section{Table 1 (on next page)}

Description of parameters in migration timing and route of four Pallas's Gulls across the Qinghai-Tibetan Plateau determined by satellite telemetry during 2006-2009. 
1 Table 1: Description of parameters in migration timing and route of four Pallas's Gulls

2 across Qinghai-Tibetan Plateau determined by satellite telemetry during 2006-2009.

\begin{tabular}{|c|c|c|c|c|c|c|}
\hline & Parameters & G1 & $\mathrm{G} 2$ & G3 & G4 & All birds \\
\hline \multirow{12}{*}{ Autumn } & No. journeys & 4 & 3 & 2 & 3 & 12 \\
\hline & Departure date & 10 Aug \pm 5 & 12 Aug \pm 12 & 13 Aug \pm 5 & 4 Aug \pm 1 & 9 Aug \pm 7 \\
\hline & Arrival date & $7 \mathrm{Nov} \pm 4$ & $11 \mathrm{Nov} \pm 6$ & $30 \mathrm{Nov} \pm 4$ & $23 \mathrm{Nov} \pm 1$ & $16 \mathrm{Nov} \pm 10$ \\
\hline & Duration & $89 \pm 9$ & $91 \pm 8$ & $110 \pm 9$ & $111 \pm 1$ & $99 \pm 12$ \\
\hline & Trans-QTP duration & $87 \pm 9$ & $40 \pm 44$ & $33 \pm 4$ & $26 \pm 2$ & $51 \pm 33$ \\
\hline & Shortest distance & $1815 \pm 7$ & $1895 \pm 27$ & $1906 \pm 131$ & $2116 \pm 84$ & $1925 \pm 133$ \\
\hline & Cumulative distance & $2009 \pm 107$ & $3375 \pm 1161$ & $3333 \pm 1010$ & $4265 \pm 170$ & $3135 \pm 1086$ \\
\hline & Trans-QTP distance & $1304 \pm 246$ & $1649 \pm 211$ & $1245 \pm 79$ & $1913 \pm 175$ & $1533 \pm 329$ \\
\hline & Speed & $23 \pm 2$ & $38 \pm 14$ & $30 \pm 7$ & $38 \pm 2$ & $32 \pm 10$ \\
\hline & Trans-QTP speed & $15 \pm 3$ & $130 \pm 154$ & $38 \pm 7$ & $75 \pm 10$ & $63 \pm 81$ \\
\hline & Straightness & $0.91 \pm 0.05$ & $0.62 \pm 0.26$ & $0.61 \pm 0.22$ & $0.50 \pm 0.02$ & $0.68 \pm 0.22$ \\
\hline & Mean altitude & $3051 \pm 350$ & $2693 \pm 276$ & $2257 \pm 20$ & $2498 \pm 11$ & $2691 \pm 372$ \\
\hline \multirow{12}{*}{ Spring } & No. journeys & 3 & 3 & 2 & 2 & 10 \\
\hline & Departure date & $2 \operatorname{Mar} \pm 8$ & $19 \operatorname{Mar} \pm 2$ & $28 \operatorname{Mar} \pm 3$ & $19 \operatorname{Mar} \pm 2$ & $15 \operatorname{Mar} \pm 11$ \\
\hline & Arrival date & $4 \mathrm{Apr} \pm 3$ & 11 May \pm 14 & 14 May \pm 22 & $26 \operatorname{Mar} \pm 4$ & $21 \mathrm{Apr} \pm 24$ \\
\hline & Duration & $34 \pm 8$ & $53 \pm 16$ & $47 \pm 19$ & $7 \pm 1$ & $37 \pm 20$ \\
\hline & Trans-QTP duration & $7 \pm 4$ & $50 \pm 18$ & $13 \pm 6$ & $6 \pm 1$ & $21 \pm 22$ \\
\hline & Shortest distance & $1831 \pm 31$ & $1856 \pm 19$ & $2008 \pm 216$ & $2256 \pm 1$ & $1959 \pm 186$ \\
\hline & Cumulative distance & $3177 \pm 191$ & $2199 \pm 125$ & $3618 \pm 1$ & $2415 \pm 136$ & $2819 \pm 602$ \\
\hline & Trans-QTP distance & $1229 \pm 45$ & $1605 \pm 142$ & $2279 \pm 572$ & $1458 \pm 207$ & $1597 \pm 446$ \\
\hline & Speed & $98 \pm 26$ & $44 \pm 13$ & $85 \pm 35$ & $351 \pm 52$ & $130 \pm 121$ \\
\hline & Trans-QTP speed & $198 \pm 85$ & $35 \pm 13$ & $196 \pm 54$ & $246 \pm 23$ & $158 \pm 98$ \\
\hline & Straightness & $0.58 \pm 0.03$ & $0.85 \pm 0.05$ & $0.55 \pm 0.06$ & $0.94 \pm 0.05$ & $0.73 \pm 0.17$ \\
\hline & Mean altitude & $2224 \pm 108$ & $3069 \pm 131$ & $3111 \pm 462$ & $2543 \pm 264$ & $2719 \pm 449$ \\
\hline
\end{tabular}




\section{Table 2 (on next page)}

GLM mixed model testing the effect of "individual" on migration timing and route with repeatability $(r)$ values.

${ }^{*} P<0.05 ;{ }^{* *} P<0.01 ;{ }^{* * *} P<0.001$. 
1 Table 2: GLM mixed model testing the effect of "individual" on migration timing and route 2 with repeatability $(\boldsymbol{r})$ values.

\begin{tabular}{|c|c|c|c|c|c|}
\hline Season & Parameters & df & $\mathbf{F}$ & $r$ & $\boldsymbol{P}$ \\
\hline \multirow{12}{*}{ Autumn } & Departure date & 3,8 & 0.80 & -0.07 & 0.527 \\
\hline & Arrival date & 3,8 & 17.35 & 0.85 & $0.001^{* *}$ \\
\hline & Duration & 3,8 & 7.06 & 0.67 & $0.012^{*}$ \\
\hline & Trans-QTP duration & 3,8 & 5.28 & 0.59 & $0.027^{*}$ \\
\hline & Speed & 3,8 & 3.39 & 0.45 & 0.074 \\
\hline & Trans-QTP speed & 3,8 & 1.35 & 0.11 & 0.324 \\
\hline & Cumulative distance & 3,8 & 6.42 & 0.65 & $0.016^{*}$ \\
\hline & Trans-QTP distance & 3,8 & 6.72 & 0.66 & $0.014^{*}$ \\
\hline & Straightness & 3,8 & 4.48 & 0.54 & $0.040^{*}$ \\
\hline & Mean altitude & 3,8 & 5.16 & 0.59 & $0.028^{*}$ \\
\hline & Longitude crossing $29^{\circ} \mathrm{N}$ & 3,8 & 9.74 & 0.75 & $0.005^{* *}$ \\
\hline & Longitude crossing $35^{\circ} \mathrm{N}$ & 3,8 & 14.55 & 0.82 & $0.001^{* *}$ \\
\hline \multirow{12}{*}{ Spring } & Departure date & 3,6 & 13.76 & 0.84 & $0.004^{* *}$ \\
\hline & Arrival date & 3,6 & 9.73 & 0.78 & $0.010^{*}$ \\
\hline & Duration & 3,6 & 5.57 & 0.65 & $0.036^{*}$ \\
\hline & Trans-QTP duration & 3,6 & 10.05 & 0.79 & $0.009^{* *}$ \\
\hline & Speed & 3,6 & 45.18 & 0.95 & $0.000^{* * *}$ \\
\hline & Trans-QTP speed & 3,6 & 7.53 & 0.70 & $0.019^{*}$ \\
\hline & Cumulative distance & 3,6 & 51.02 & 0.95 & $0.000^{* * *}$ \\
\hline & Trans-QTP distance & 3,6 & 6.64 & 0.73 & $0.025^{*}$ \\
\hline & Straightness & 3,6 & 35.78 & 0.94 & $0.000^{* * *}$ \\
\hline & Mean altitude & 3,6 & 8.62 & 0.76 & $0.014^{*}$ \\
\hline & Longitude crossing $29^{\circ} \mathrm{N}$ & 3,6 & 20.06 & 0.89 & $0.002^{* *}$ \\
\hline & Longitude crossing $35^{\circ} \mathrm{N}$ & 3,6 & 27.00 & 0.91 & $0.001^{* *}$ \\
\hline
\end{tabular}




\section{Figure 1 (on next page)}

Map showing the repeat migration tracks of four Pallas's Gulls between Qinghai Lake, China, and Bangladesh Bay determined by satellite telemetry during 2006-2009.

Solid dark grey lines indicate spring migration routes and dashed dark grey lines indicate autumn migration routes. Background grey shows the Qinghai-Tibetan Plateau above $3000 \mathrm{~m}$ in altitude. A total of 12 complete autumn and 10 spring migration routes were recorded. A-D represent for G1-G4, respectively. 

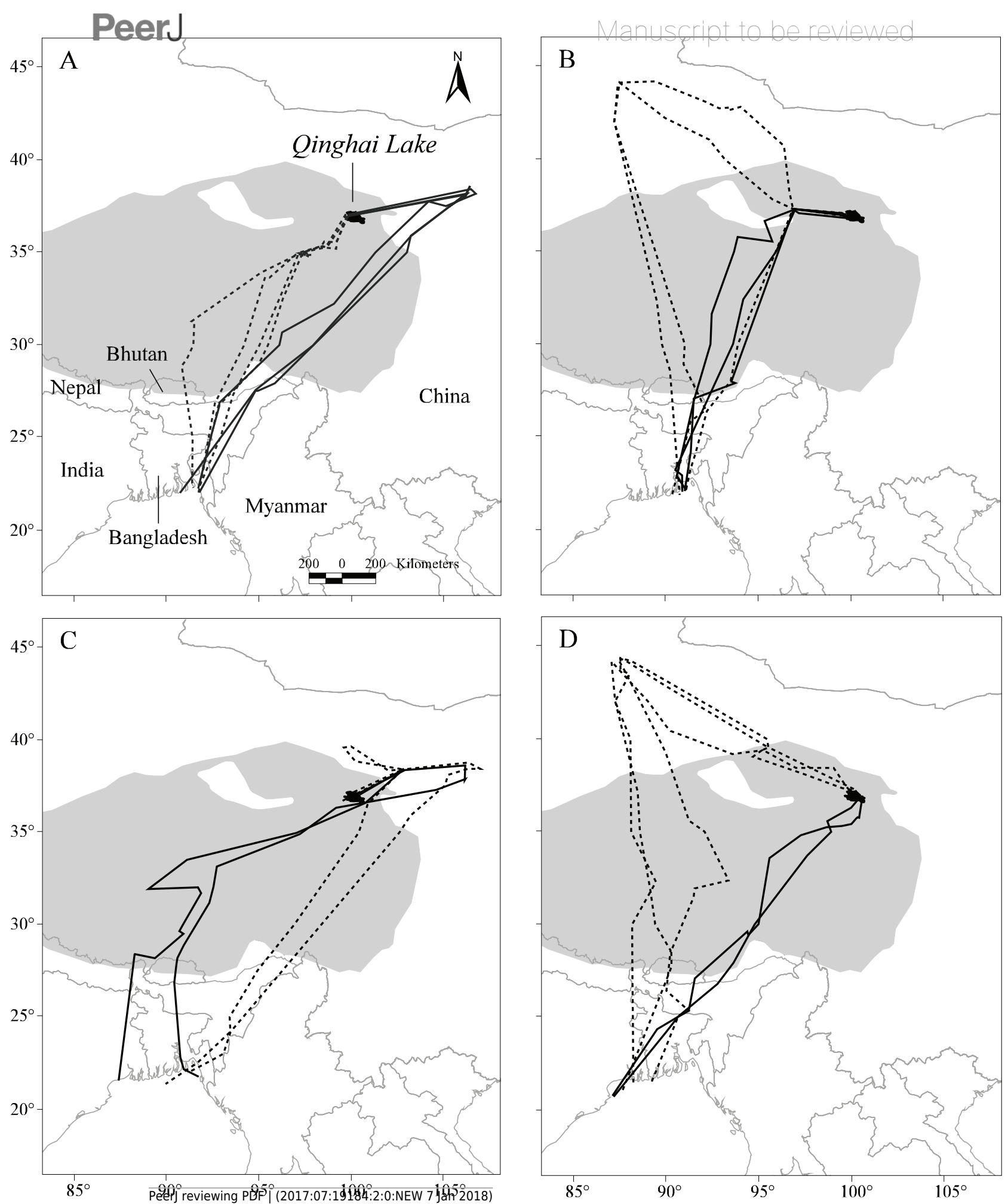


\section{Figure 2 (on next page)}

Bar plot showing the mean longitudinal deviation of observed routes from the expected shortest routes in latitudinal bins of three degrees, for autumn (black) and spring (white) migrations.

Error bars show standard deviation, pie charts show proportion of routes that deviated significantly $(p<0.05)$ from 1000 randomised routes starting and ending at the same point. 


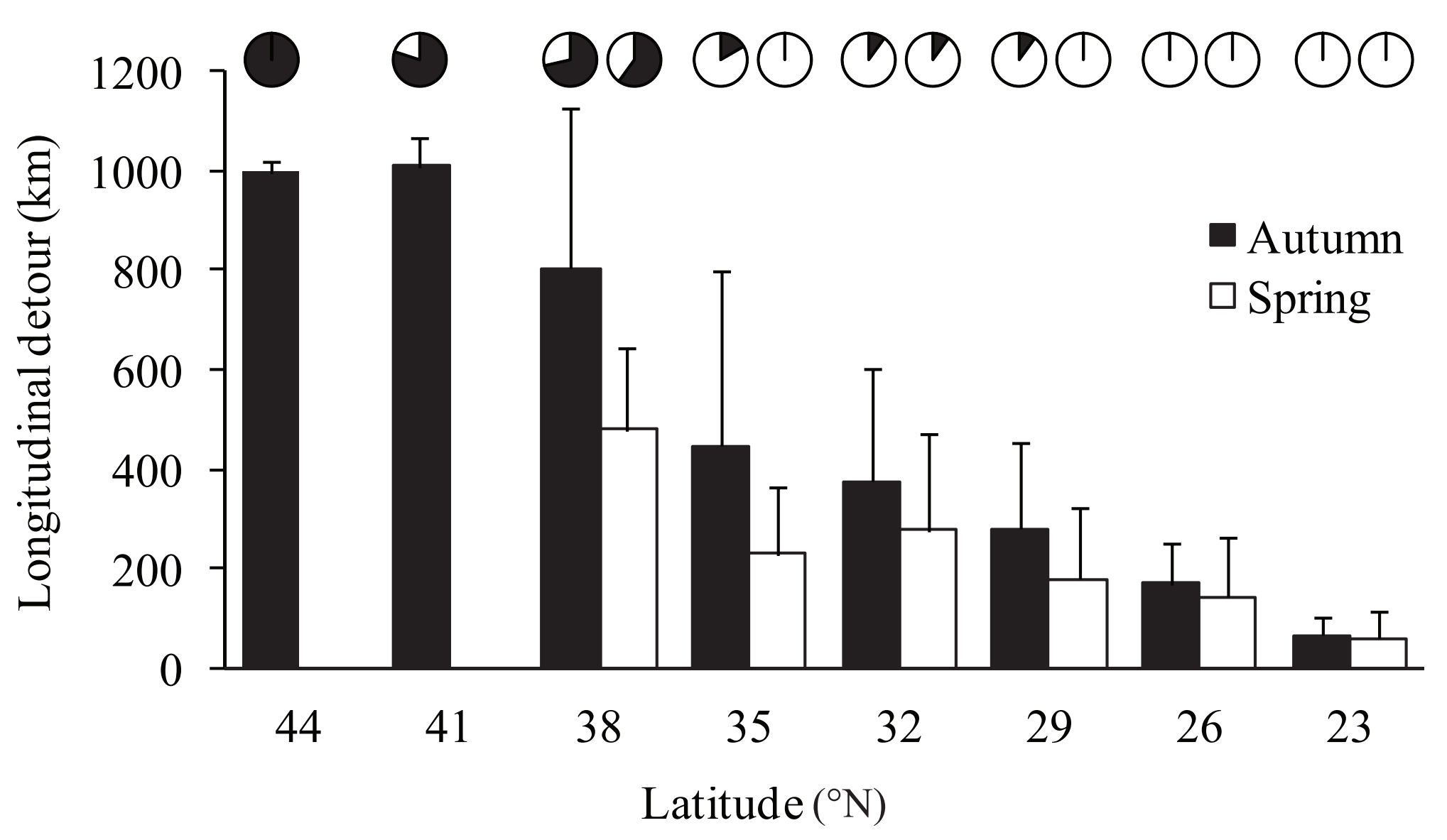




\section{Figure 3 (on next page)}

Line plots showing comparison of proximity to water bodies along expected shortest routes and observed routes during autumn (A) and spring (B) migration of Pallas's Gulls.

$* \mathrm{P}<0.05$, n.s. indicates $\mathrm{P} \geq 0.05$. Significance levels were based on paired t-test. 
PeerJ

Autumn

Manuscript to be reviewed Spring

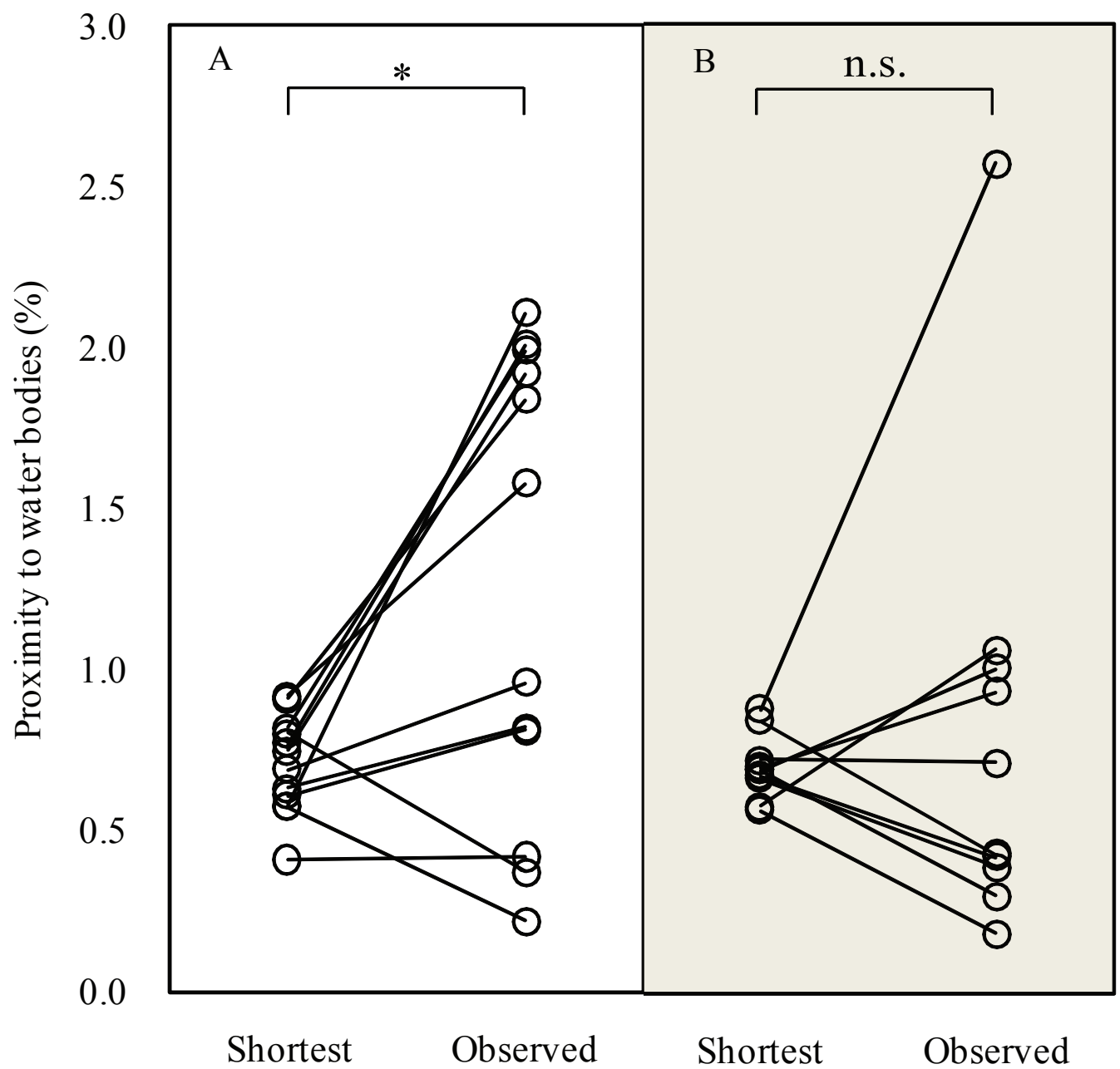


Figure 4 (on next page)

The movement locations of Pallas's Gulls and habitats at detoured stopover sites with low altitude indicated by Google earth.

A-Qinggeda Lake in Wujiaqu City, B-Lakes in Wulumuqi City, C-Hongyashan Reservoir in Minqin County, D-Yellow River in Yinchuan City. All these stopover sites are characterized by water bodies which were used as key fuelling sites for moulting and trans-QTP flights. 


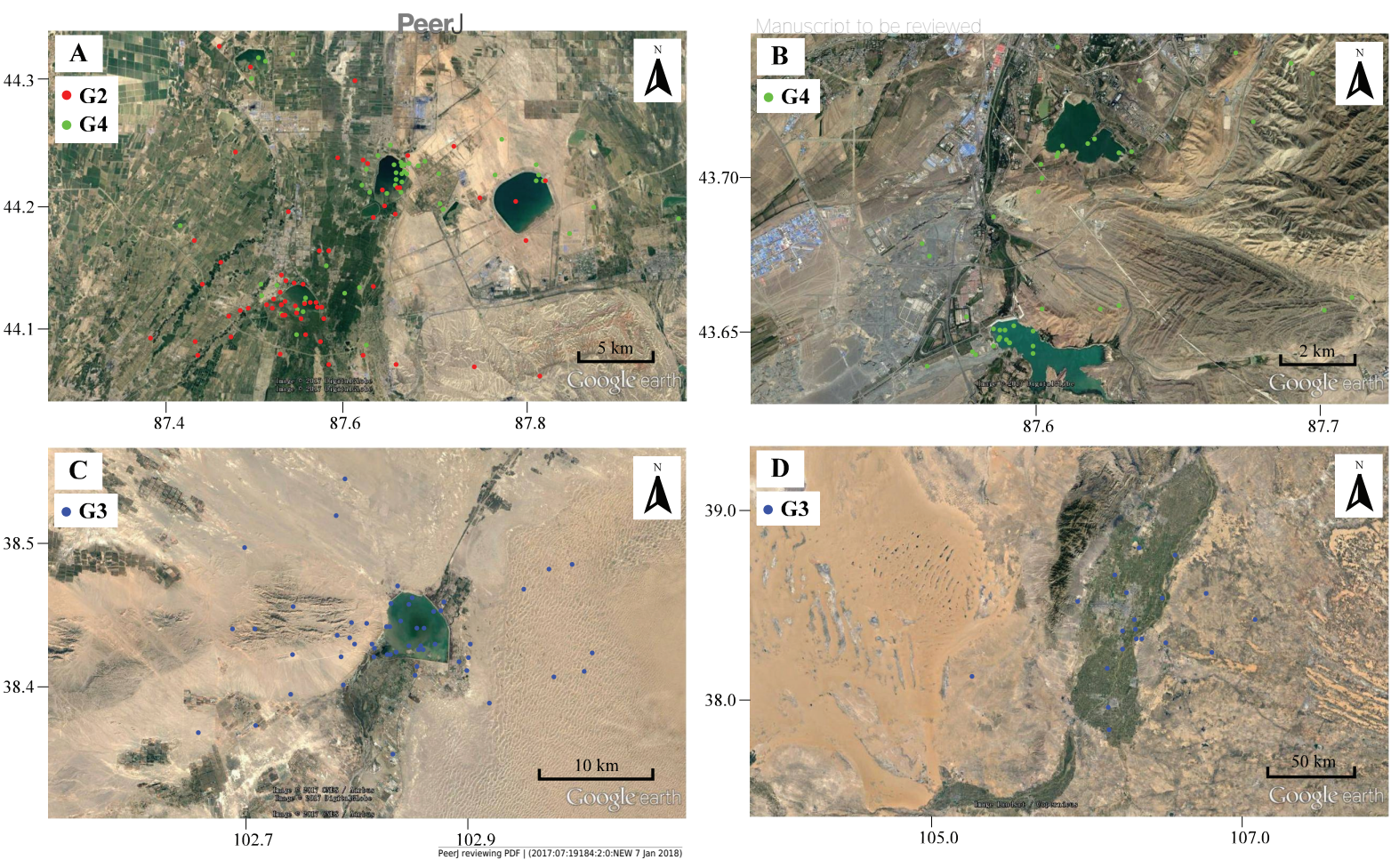




\section{Figure 5 (on next page)}

Line plots showing differences in ground surface temperatures between the breeding ground at Qinghai Lake (solid lines) and overshot stopover site on a stretch of the Yellow River stretch (dashed lines).

This figure exemplifies the influence of cold weather on detours in spring. One gull (G1) overshot the frozen breeding ground at Qinghai Lake and stayed at the warmer Yellow River from mid-March to early April in 2007 (red lines), 2008 (blue lines) and 2009 (green lines). Temperature were extracted from the local meteorological stations from NOAA (available at https://gis.ncdc.noaa.gov/maps/ncei\#app=clim\&cfg=cdo\&theme=hourly\&layers=1\&node=gi s). 


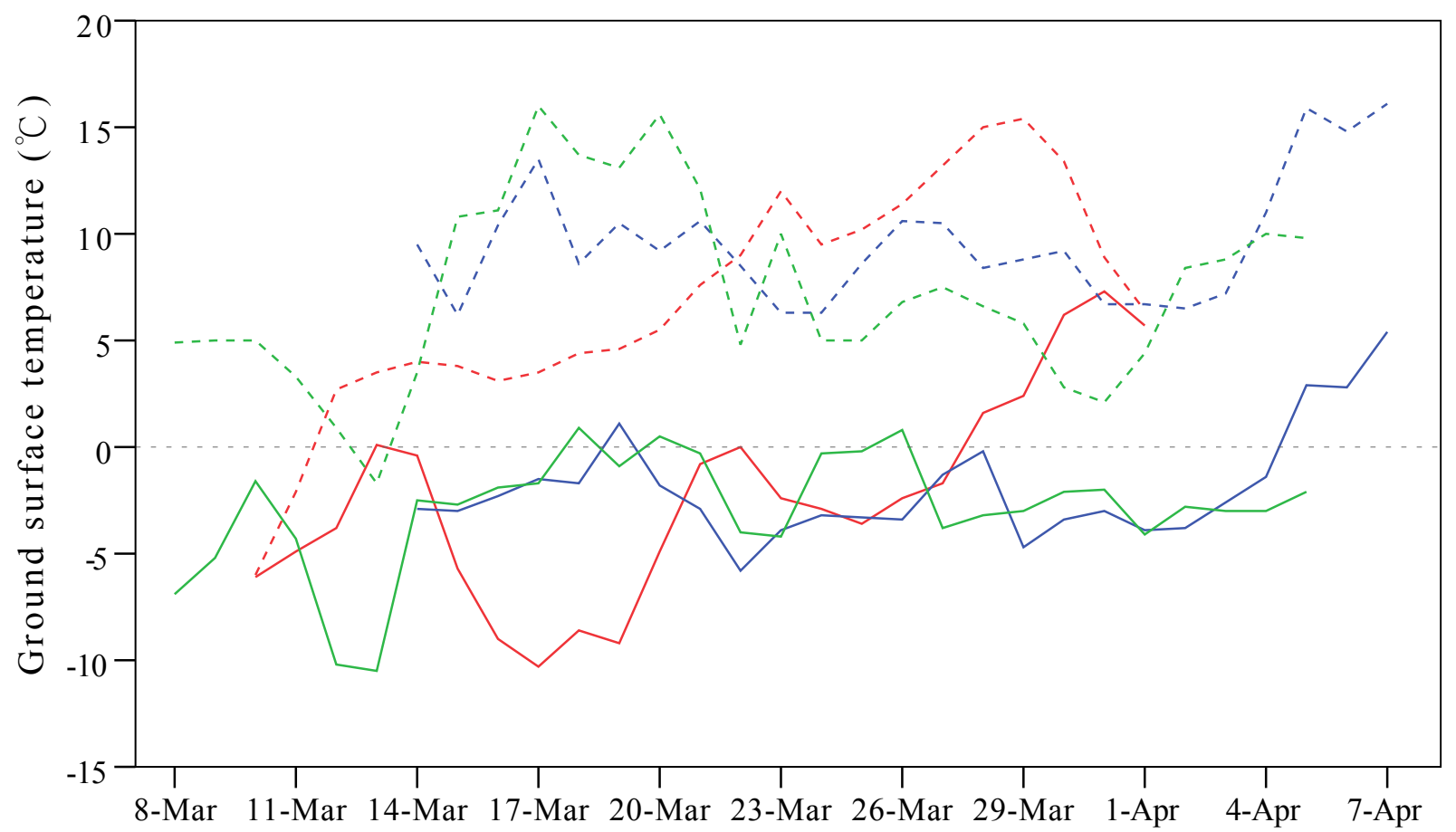

